\title{
School Literacy Practices Closer to Home: the New Challenge of Literacy Learning
}

Luz Mary Quintero

\begin{abstract}
Literacy learning/teaching can be an unforgettable experience when it is a joint effort between school and home. There are family literacy practices and traditions that can bring about amazing outcomes when they are conjugated with school literacy activities. This article attempts to suggest some possible ways for teachers and parents to work collaboratively to make the journey of becoming literate a much more rewarding path for both children and teachers. The perspectives presented here are based on experiences that some teachers have lived by working with parents, and on some theoretical perspectives. It is an invitation for us, teachers, to reflect upon our literacy practices we promote in our classrooms and think of possible alternatives to make children find reading and writing a meaningful and enjoyable route.
\end{abstract}

Key words: literacy, reading, writing, school practices, household knowledge, sociocultural artifacts, knowledge construction

\begin{abstract}
El aprendizaje/enseñanza de la lectura y la escritura pueden ser una experiencia inolvidable cuando éstas son el resultado de un esfuerzo conjunto entre la escuela y el hogar. Existen prácticas y tradiciones familiares de lectura y escritura las cuales pueden traer resultados asombrosos cuando éstas son conjugadas con las prácticas de lectura y escritura desarrolladas en la escuela. Este artículo presenta algunas alternativas para ayudar a padres y educadores a trabajar colaborativamente para que el camino de la alfabetización sea una experiencia gratificante tanto para los niños como para los educadores. Las perspectivas que aquí se presentan están basadas en algunas experiencias de educadores que han trabajado conjuntamente con las familias de los niños como también con base en algunas consideraciones teóricas. Esta es una invitación a reflexionar en las prácticas de alfabetización que promovemos en nuestras clases y a pensar en posibles alternativas para hacer que los niños encuentren la lectura y la escritura una ruta significativa y placentera.
\end{abstract}

Palabras claves: alfabetización, lectura, escritura, prácticas escolares, conocimiento doméstico, artefactos socioculturales, construcción del conocimiento.

* Received: 07-02-06 / Accepted: 05-09-06 


\section{Introduction}

Traditionally, literacy learning has been associated with school practices. It is generally thought that learning reading and writing only takes place in school based activities. Thus, neither parents nor students seem to be aware of the richness some of their family practices and traditions may have in their learning. Literacy practices do not start and end at school; it is only the place where formal instruction takes place. During the last decades, many teachers as well as researchers have considered the alternative of integrating family practices within school settings. It is not very easy to make big changes in teachers' and parents' and even students' beliefs about literacy. Since we are used to doing the same kind of things, we think that because students in the end learn to read and write, it means that the system is good. Nevertheless, in the majority of cases school based activities seem to be disconnected of the real purposes for which children use these practices. Schultz $E$ Hull (2002) put it as follows "Yet despite the dazzling theoretical advances of how we conceive literacy, despite provocative research on out-of-school literacies in an array of interesting settings, a depressing fact remains: We still have not succeeded in improving the educational experiences and life chances of the vast majority of children, adolescents and adults" (p. 18). Evidently, theory is not enough to make a change, but teachers must be aware that the need is great and that we must give the best of our resources towards improving the life chances of all those children whose only possibility to have a better life is school. So, how, when and where to start making the change?

One of the ways in which parents' voices are brought into school is through integrating family literacy practices to the literacy activities students carry out at school. Another way is by transferring household knowledge to academic work in classrooms. In fact, in these out-of school contexts, rather than in school-based ones, many of the major theoretical advances of literacy have taken place. Exploration of these two important issues will give us insights on how to bridge communities of literacy learning where socio-cultural artifacts are valued in learning.

\section{Sociocultural Artifacts and Knowledge Construction}

Traditionally, knowledge has been treated as a property of recognized intellectuals whose everlasting ideas are kept in books. Normally, knowledge 
is seen as those theoretical and scientific issues that have, somehow, changed the course of life. In this trend of thought, education is the machinery in charge of transmitting that knowledge from generation to generation as something already given. Steiner E Meehan (2000) state: "During periods of rapid industrialization, scientists and educators have addressed primarily the transmission of knowledge and skills rather than the transformation of knowledge and skills" (p.31). In doing so, students' personal realities and experiences are valued neither by the educational system nor by teachers but they have to consume all the pre-formulated trends of knowledge. Wells (2000) refers to this as follows: "The prevailing view is that knowledge is commodity that is stored either in individual minds or in texts or other artifacts... It can also be itemized, quantified and measured...all that students need to do is to read and listen attentively to the knowledge conveyed through authoritative texts and lectures, and absorb and remember it for subsequent reproduction" (p. 67) Thus, students do not have the possibility of creating or recreating knowledge, but only of receiving information that then is just repeated but not internalized nor understood. As a result, we have students filled with a lot of information which they are unable to relate to something closer to their real lives or at least to the real world. Perhaps most of us, at some point of our lives as students, have felt that there have been hundreds of things that we can repeat but that we are not able to arrive to understand. It commonly happens at school with mathematics, physics, chemistry, and even with Spanish; students learn a formula and then apply it in a "problem" and solve it. Do they know what the connection with the real world is? In most of the cases the answer is no; however, they do well at school.

Similarly, the concept of culture is regarded as some bounded traditions that help differentiate groups of people (Moll, 2000). This approach to culture embraces complete groups of people in a given place. Nevertheless, there are very particular activities at the interior of each family that make it different from that big group of people. One tends to think of the whole, forgetting each individual who makes up that society. Evidently, even though that individual makes part of that big group, he has certainly very particular and personal experiences that make him different from the general culture he lives in. Moll's (2000) asserts: "We argue for a focus on the processes of how people live culturally. There is no clearly defined culture...These static notions of culture do not take into account the everyday experiences of children and families, 
which may or may not coincide with normative cultural behaviour" (p. 267). Such a vision of culture gives room for the inclusion of particular individuals with diverse cultural resources that mediate in the construction of knowledge. There are, sometimes, little and maybe not very meaningful situations in each family that make them have a different conception of the world, in Moll's words, cultura vivida. According to Vygotsky (cited in Moll, 2000) this perspective rejects the idea of conceiving culture just as that broad variable that make people different across nations and populations, culture is also the social milieu in which the life of the people is embedded. Consequently, knowledge and culture are intrinsically joined, since knowledge is constructed or reconstructed on each individual's experience and information derived from other sources to bear in solving some particular problem. It is important to consider culture not as a normative model, but as a practice, as an activity. Nonetheless, not all of them are equally relevant for the development and growth of each individual but it is mediated by the individual's actions and right thinking.

During the last decades, based on Vygotsky's theories, researchers have addressed their attention towards the recognition of the socio-cultural sources of development of communities and how the interaction of those local community practices shapes the learning processes and development of the individuals. To do so, they have done ethnographic analyses of households. The purpose is for teachers to develop both theory and methods to identify and document the cultural resources found in the immediate school community, as represented by the children's households that could be used for teaching (Gutiérrez and Stone, 2000). Household knowledge may include information about farming and animal management, associated with households' rural origins, or knowledge about construction and building, related to urban occupations, as well as knowledge about many other matters (Moll et al.,1992, 133).

Moll et al. carried out a research for studying household and classroom practices within working class, Mexican communities in Tucson, Arizona. To accomplish the goal, they worked collaboratively with teachers and anthropologists. They had to visit every house of every student. It was not the typical visit to talk about the things that children did wrong at school. Instead, researchers observed and talked to families to know what their home practices were. It was a long process but at the end the outcomes were amazing. There was a much closer relationship among parents, children, and teachers. It allowed teachers to know a lot about the families and to include 
all that knowledge into their teaching. They designed learning units based on the information gathered from students' households. As it is seen, with this educational picture learning does not start at school; instead, it is another step in students' learning. Moll's work demonstrates us how funds of knowledge can be used to bridge communities to classrooms by acknowledging the expertise of parents and community members; and how both, house and school can work collaboratively to build up learning communities in which every one has something to teach. Vygotsky asserts it as follows: "Learning begins out of school and is a continuous cycle that must not be static" (cited by Ball 2000, p. 245)

With these ideas in mind, we move to the literacy teaching settings. Knowledge in its broadest conception is something that initially is constructed in our minds. Ideas, beliefs, and conceptions are at first whole parts stored in our brains; however, we have the need of language as a very important vehicle to make them be known. The facilitation of language use within a sociocultural environment is the predominant means by which people make sense or meaning (Wells, 2000). "Language serves as a conceptual organizer, primary medium through which thinking occurs" (Lee, 2000, p. 192)1. Thus, language is above all an inherent part of knowledge construction. So, the idea of literacy teaching should be to help learners shape their ideas through language rather than only providing them with formal instruction of the language system. What is really necessary at school is to help students become readers and writers who use their respective skills as powerful tools that allow them to rethink the world and reorganize their own thinking (Lerner, 2001). The student is the subject of the process of learning to read and write as an act of knowing and of creating (Freire 1987).

Literacy learning arises in social environment; thus, it involves students' everyday life. Also, the experience that every student has with reading and writing varies according to family practices which in some cases are not used at school maybe due to the very rigid system of education that does not look at students as belonging to a society in which they are always involved and which shapes their learning experiences; or due to the lack of interest of the teacher in knowing the students' experiences. It is important for educators to understand the kind of language experiences children have had and the process that underlies their language learning so that they can help them build school literacy practices on these skills and experiences. As Goodman 
(1996) argues, children are involved in many households that have a great influence in learning to read and write. There are particular family rituals -he says - that make reading and writing meaningful to children. For instance, reading newspapers, magazines, comic books, filling crosswords, writing notes and family cards, participating in Bible reading and giving an oral interpretation of it; or simply by writing short notes to prevent siblings from entering their bedrooms. Children are engaged in active reading and writing in out of school activities, perhaps, not the formal reading and writing they do at school the same thing. Unfortunately, those home experiences are very often unknown or unappreciated by educators. Many teachers are too hurried about teaching letters and vowels that they forget that reading and writing is much more than joining fragmented pieces.

In more than three years of participant observation in home and school contexts with seven Cambodian girls in Philadelphia, Ellen Skilton (2002) came to the conclusion that there is a big separation between school literacy and home literacy. These girls were actively engaged in different literacy activities totally ignored in the school context. The researcher focused her attention principally on a girl whose school performance was very poor. Writing at home for the girl was an enjoyable experience; she was totally engaged in the process. She did it as a way to tackle tough subjects and to create fantasies. Writing for her meant, foremost, to create something that could be read to an audience. There were many mistakes in her writing but when she performed it orally she paraphrased what was in the piece of paper. She usually reinvented a much more difficult story as she read during the performance. Skilton (2002) points out that reading texts orally fits with a tradition in Cambodia whereby performance is an essential aspect of reading. Orality, visual imagery, and literacy for Cambodians are important tools for the transmission of culture. They view performance as part of reading across generations. In the same way, in Cambodian houses - reports the researcher - it is videos, photographs of family members, and posters of scenes from Cambodia (not books or magazines) what allow Cambodians in Philadelphia to remain connected to their homeland. Interestingly, even though the girls were in a context of English literacy learning, they continue to use performance and oral reading in their literacy practices; as well as to use a lot of pictures to supplement the meaning of their written texts.

In spite of reading and writing a lot at home, the girl was not a good writer at school. The teacher used to complain about her performance, and used to 
say that she would not be able to start the next grade. Sadly, those cultural traditions were ignored at the girls' school. Writing at school was imposed by the teacher. She decided about the topics, the genre, and even the length of the piece of writing. I wonder if these girls' teachers knew something of their cultural background and how rich it was if brought into their school literacy practices. The experience she had out of school setting was real; it had a purpose. She used the power of the written word to convey meaning and build relationships.

\section{Parents' Involvement}

We have pointed out that when children arrive to school, they already know lots of things about reading and writing thanks to those very particular practices families have. At each home, there must be a special literacy practice that makes it more attractive to children. As Goodman (1996) suggests, there is no single road to literacy. It is easier for children to go on learning about reading and writing when their daily literacy routines are included in this process. (Hannon, 1995) affirms: "Not only do parents have a deeper, more powerful, relationship with their own children than teachers can aspire to, but parents are better placed to exploit those moments in the day from waking time to bedtime, when children's desire to read is at its strongest and when they find the activity most meaningful" (p. 74). One of the activities we may tend to think when we think of how to involve parents in the literacy process is reading alouds since it is perhaps the most familiar to us. In spite of having good results with this practice, researchers have shown that there are other ways in which parents can contribute to develop their children's literacy no matter how traditional those practices may be. Let us see other ways to involve parents in this amazing process of learning to read and write.

Barillas (2000) shares her experience of bringing parents' voices to her classroom. She asserts: "As educators it is essential that we invite parents to share their experience and knowledge of their culture with their children" (p. 302). She had the brilliant idea of having children do writing activities at home together with their parents or siblings. This program was developed with American and Mexican American, with a few Central American students. The first year they wrote letters of advice, the second year they, parents and children, wrote poems entitled "I Am" and letters of advice. For parents to do 
these writing tasks, the teacher sent some prompts or patterns to help them. The third year, they did not receive any guide, they had to respond to the 1990 Nobel Prize acceptance speech of the Dalai Lama as part of a unit on the lives of Martin Luther King, Jr. and Cesar Chávez, as part of a component of peace and conflict resolution curriculum. The purpose was to engage parents in meaningful literacy activities that they could share with their children. The results were amazing: children were willing to write at home with their parents; they would arrive with poems and amazing stories written at home through their parents' unique perspectives and experiences. Never had she seen her students so eager to write as that year. Writing activities were varied from poems and stories to personal experiences and very personal positions towards certain topics. Children were not forced to write unreal stories based on five or ten words given by the teacher on the board, or the same story about vacation, or as the very physical activity of transcribing from a textbook to the notebook. Writing was, instead, something real and connected to students' real lives. Consequently, writing has a purpose and thus it is done with much more motivation. Freire (1987) says: "Words should be laden with the meaning of the people's existential experience, and not of the teacher's experience" (p. 27 ). The key point is that human beings and their social and cultural worlds are inseparable. They are embedded in each other (Moll, 2000). Literacy, therefore, is not simply knowing how to read and write a particular script, but applying this knowledge for specific contexts of use.

Accordingly, learning is always mediated by the interaction among members of a given society whose beliefs and traditions have a very evident relation with the individuals and their conception of the world. Even though we belong to something that we call "culture", each family has its own "culture" that underlies its existential experiences. As a result, what they live everyday is different from others' experiences. "The student is the subject of the process of learning to read and write as an act of knowing and of creating." (Freire, 1987; 25). Consequently, literacy learning is quite an individual creative task.

Similarly, Harding (1996) gives insights into how to involve parents in literacy activities. It was a very interesting activity because not only children but also parents were engaged in writing. Children were in kindergarten. That means that they were beginning the process of reading and writing. Children took books home from the school and they read the pictures to them. They just created their own story based on the pictures and then parents read the 
actual story that was written in the book. At the beginning it was difficult since children felt ashamed to read because they did not know how to read words. Afterwards, children gained confidence as they saw that their parents valued the stories they created from the pictures. As the teacher did not have time to talk to each parent about how the reading process was going on, she decided to ask them to write a journal. In this way, they could share what each reading experience was like everyday. They could write about the way children behaved, if they had enjoyed the story, the kinds of questions they had posed, and even about the tasks children loved doing at home. The results were really gratifying. Children as well as parents were involved in the reading and writing process. Such activity suggests that children are able to construct meaning from and for texts even though they do not know how to read or write, formally speaking. When these kinds of readings take place, children learn to read and write with the idea that they are linked to real purposes that go beyond writing complete pieces of paper with the same meaningless sentence, or reading phrases that do not tell them anything.

Another way to involve parents in their children's literacy learning is by encouraging them to listen to their children read to them (Hannon, 1995). Normally, we have heard of reading aloud as an activity that parents do with their children. What parents do is to read stories to their children, usually at bed time. But Hannon proposes parents to listen to their children read at home as an activity full of teaching and learning possibilities.

But what kind of texts should be chosen to be read? There are thousands of good children's books to be read; however, books are not the only thing children are interested in, nor what necessarily counts as appropriate. Newspaper, cornflakes, advertisements, road signs, and even flash cards can be appropriate in some circumstances (Hannon, 1995). It might be of great help for those parents who cannot afford a lot of books. Children are amazingly motivated to read many stories or situations that are not in books, but that make part of their surroundings and personal interests. However, parents' task is not only to listen to their children reading, but also to provide appropriate interaction when the child actually attempts to read. The first thing parents should think of is helping children make sense of what they read, as well as provide feedback and assistance on reading. In this sense parents can contribute a lot because they have much more chance to help their children since at school the teacher has many students to listen to; so that they help only to a limited 
extent while parents can devote far more time to listening and talking to them. Hannon (1995) could see that many children from working-class families had virtually no suitable reading materials at home. Sending school reading books home in such circumstances could have a considerable impact on children's opportunities to learn to read.

This parents' involvement not only helps children and teachers to develop literacy for purposes closer to students' real lives and to see the social use and the power of being literate, but also brings families together. In this world where communication has little by little become a thing of the past, there is less time for the families to spend talking to each other, television has, somehow, displaced family meetings. Schools must play an important role in trying to help parents be conscious of the crucial importance of spending some time every day with their children. We find thousands of lonely school children who would give anything in order to have their parents by their side at least some minutes of the day. With these experiences we can see how parents and children were engaged in doing common activities and in that way devoting some time to being together as a family.

\section{Conclusion}

A successful academic experience is linked to the quality of language experiences that children have at home and how these are extended in school. Researchers, educators and parents have suggested that the environment at home is a likely source of experiences that can enhance the development of literacy. Unfortunately, sometimes passion and attraction for reading and writing ceases when children enter school because the literacy practices in the classrooms are boring routines of handwriting or readings that only cover the phonemes children have studied. Moreover, in many schools language is sequenced and given to children by little pieces that are learned or memorized in such a mechanical way that children do not see any real use. Thus learning to read and write is reduced merely to learning vowels, then consonants and then joining syllables that make up words. Needless to say, language is the means to construct meaning. Without language, our thoughts would be unknown by others. Language is the essential condition of knowing the process by which experiences become knowledge.

Here lies the challenge for us as educators. Individuals must be the centre of our educational system. Before being students, children are part of 
a socio-cultural community that (re)shapes their daily life experiences and consequently their conception of the world. We must think of education as the arena where people find different alternatives to re-create new worlds of inclusion for those who are voiceless in a world where only the privileged spheres of the society can be heard. As we have seen, there is not just one culture. We certainly belong to a general group of people with cultural practices that makes us different from others; however, each family has very particular beliefs, rituals, practices and traditions that portrait the whole behavior of the members, and mediate the construction of knowledge. Moll (2000) highlights the importance of how people live culturally. He points out: "We argue for a focus on the process of how people live culturally. There is not clearly defined culture out there in the world, these static notions do not take into account the everyday lived experiences of children and their families which may or may not coincide with normative cultural behaviour" (p. 267).

To know how our students live culturally demands big efforts from us, but we will achieve much more gratifying results in students' performance at schools and as individuals in our society.

\section{References}

Ball, A. (2000). Teachers' developing philosophies on Literacy and Their Use in Urban Schools: A Vygotskian Perspective on internal activity and Teacher Change. In Lee, C. \& Smagorinsky, P (Eds.), Vygotskian Prespectives on literacy research. Construcuting meaning through collaborative inquiry. (pp. 226-255) Cambridge: Cambridge University Press.

Barillas, R. Literacy at home: Honoring parent voices through writing. The reading teacher journal, 54(3), pp. 302-308.

Freire, P. \& Macedo, Macedo, D. (1987). Literacy: reading the word and the world. Westport, CO., Bergin \& Garvey.

Goodman, K. (1996). On reading. Porstmouth, NH, Heinemann.

Gutiérrez, K. \& Stone, L. (2000). Synchronic and Diachronic Dimensions of Social Practice: An emerging Methodology for Cultural-Historical Perspectives of literacy Learning. In Lee, C. \& Smagorinsky, P (Eds.), Vygotskian Prespectives on literacy research. Construcuting meaning through collaborative inquiry. (pp. 226-255) C a m b ri dg e : Cambridge University Press.

Hannon, P. (1995). Working with parents of school-age children. In Hannon (1995). Literacy, home and school: Research and practice in teaching literacy with parents. 
Harding, N. (1996). Family Journals: The bridge from school to home and back again. Young Children Journal, pp.27-30.

Lee, C. (2000). Signifying in the Zone of Proximal Development. In Lee, C. \& Smagorinsky, P (Eds.), Vygotskian Prespectives on literacy research. Construcuting meaning through collaborative inquiry. (pp. 191-255) Cambridge: Cambridge University Press.

Lerner, D. (2001). Leer y escribir en la escuela: lo real, lo posible y lo necesario. México: Fondo de Cultura Económica.

Moll, L. et al. (1992). Funds of knowledge for Teaching: Using a Qualitative Approach to connect Homes and Classrooms. Theory into Practice, 31(2), pp. 132-140.

Moll, L. (2000). Inspired by Vygotsky: Ethnographic Experiments in Education. In Lee, C. \& Smagorinsky, P (Eds.), Vygotskian Prespectives on literacy research. Construcuting meaning through collaborative inquiry. (pp. 256-268)). Cambridge: Cambridge University Press.

Schultz, G. \& Hull K. (2002). Locating literacy theory in out-of-school contexts. Contexts. In Schultz, G. \& Hull K, School's out! Bridging out-of-school literacies with classroom practice. New York: Teachers College Press.

Skilton E. (2002). Literate at home but not at school. In Schultz, G. \& Hull K, School's out! Bridging out-of-school literacies with classroom practice. New York: Teachers College Press.

Steiner, V. and Meehan, T. (2000). Creativity and Collaboration in Knowledge Construction. In Lee, C. \& Smagorinsky, P (Eds.), Vygotskian Prespectives on literacy research.

Construcuting meaning through collaborative inquiry. (pp. 31-48) Cambridge: Cambridge University Press.

Wells, G. (2000). Dialogic Inquiry in Education. Building on the legacy of Vygotsky. In Lee, C. \& Smagorinsky, P (Eds.), Vygotskian Prespectives on literacy research. Construcuting meaning through collaborative inquiry. (pp. 150-64). Cambridge: Cambridge University Press.

\section{THE AUTHOR}

Luz Mary Quintero holds an undergraduate degree from Universidad Industrial de Santander. She is currently working at Universidad Distrital Francisco José de Caldas. She is an assistant researcher of the group Lectoescrinautas from the Masters Program in Applied Linguistics at Universidad Distrital. E-mail: luzmaq03@yahoo.com 